\title{
Facilities for mentally impaired patients: three years experience of a semi-secure unit
}

\author{
Janet Mayor, Research Officer; Milan Bhate, Consultant Psychiatrist; Hugh FirTh, \\ Clinical Psychologist; Anne Graham, Department Manager; PaM Knox, Charge \\ Nurse, RMNH; and STEPHEN TYReR, Consultant Psychiatrist, Prudhoe Hospital, \\ Prudhoe, Northumberland NE42 5NT
}

The Working Party on Security in NHS Hospitals (The Glancy Report, DHSS, 1974a) and the interim report of The Butler Committee (DHSS, 1974b) both recommended that secure provision should be made available for the treatment of mentally disordered patients who required greater security than could be provided in a standard hospital setting. They recommended that patients with mild or borderline mental handicap should be treated together with the mentally ill but that "severely subnormal patients" should be treated separately. Later the Royal College of Psychiatrists (1981) largely endorsed this advice proposing that:

(a) individuals with borderline and mild mental handicap could be adequately treated in the secure units for mentally ill individuals

(b) individuals with moderate mental handicap needed a special secure facility

(c) individuals with severe mental handicap did not need high security, and should be managed in high-staffed wards in mental handicap hospitals.

In practice, the development of these units has not proceeded according to these recommendations. Although secure units for the mentally ill were developed following the Butler Report, these have been largely concerned with the care of the mentally ill and not with the mentally handicapped. This paper describes the service provided during the first three years of a semi-secure unit developed for the treatment of offenders with mental handicap and for those requiring greater security than can be provided in a normal hospital setting.

\section{Development of the Unit}

The Unit, a purpose-built, locked building, is sited at Prudhoe Hospital and is part of the adult psychiatry service to people with mental handicap from within the five districts of the sub-Regional catchment area, which has a population of 0.9 million. It has been estimated that 20 secure places might be necessary for this population for individuals with mental handicap (Oxford Regional Health Authority,
1976). There is controversy about this figure and the Unit was commissioned with 12 beds. The original operational policy for the Unit stated patients would stay for a maximum of two years, as recommended in the Butler Report, and would then move on elsewhere, but for reasons discussed later this policy has now been altered.

Referrals are made through the two consultant psychiatrists providing a service to the catchment area. Admissions normally follow assessment by the consultant, a nurse, and another member of the team. Emergency admissions are made by the consultant in conjunction with the senior nurse in charge. A treatment plan is devised within three weeks of admission, detailing the presenting problems and proposed treatment. These plans, periodically revised, are used as a basis for weekly team meetings for each individual. Informal patients may be admitted if they require very high levels of supervision. A separate arrangement provides for the occasional patient to be transferred for short periods (up to 72 hours) from the two other adult psychiatry wards and elsewhere in the hospital for the management of acutely disturbed behaviour. Three seclusion rooms were originally provided but only one is now used, and this infrequently.

The Unit is staffed by 26 nursing staff, of whom 13 are qualified nurses. Two consultant psychiatrists, two to three junior medical staff, a clinical psychologist, social worker and senior occupational therapist, provide sessions to the Unit as part of the adult psychiatry service.

Unit policy is to provide a structured day with an expectation that all patients will work, either in a semi-secure workshop, or elsewhere in the hospital. Some attend work at Adult Education placements in the community where transport can be arranged. A simplified incentive scheme to encourage work, relevant leisure activity and individual target behaviour, is intended to facilitate the smooth running of work and daily routine. Earlier attempts to provide more individualised incentive schemes for individual patients were judged to be ineffective and were discontinued. 


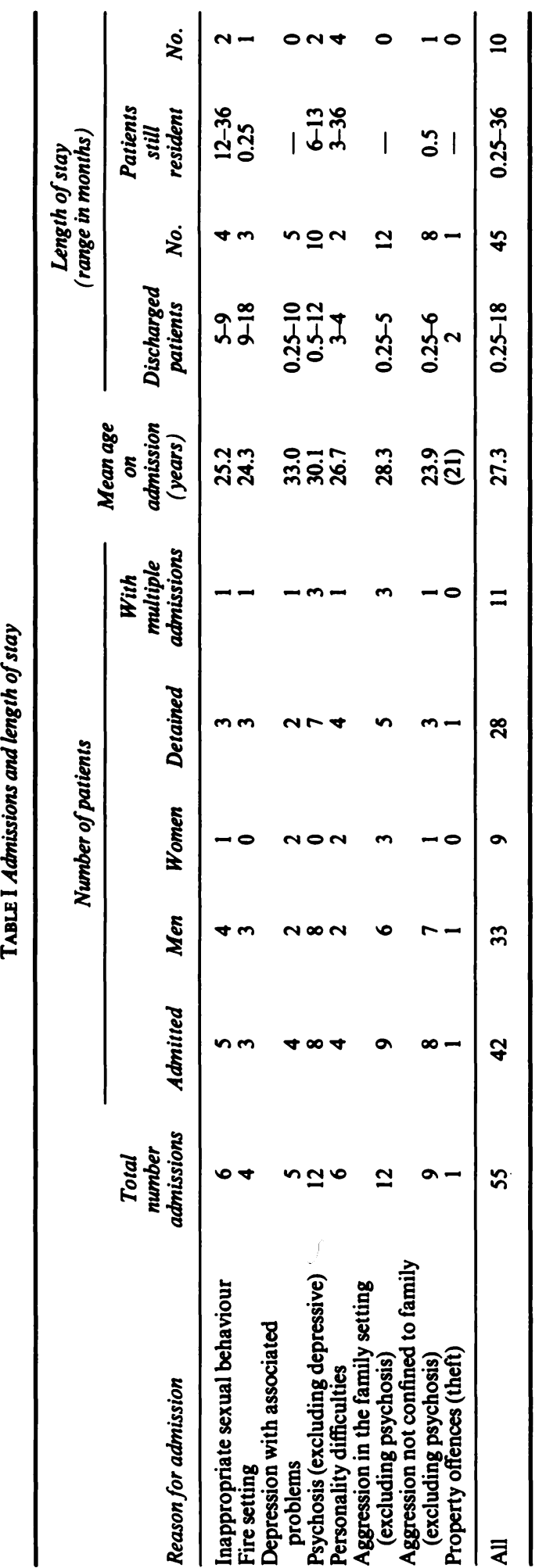

\section{The service provided}

During the first three years of the service, 42 individuals were admitted to the Unit (11 more than once). Reasons for admission have included aggressive behaviour with or without associated psychosis, depression, unlawful sexual behaviour, firesetting and offences against property (see Table I).

The three major origins from which patients were admitted were parental homes or independent accommodation, $15(27 \%)$; other treatment wards, $15(27 \%)$; and the Courts, $11(20 \%)$. Seven (13\%) were from Local Authority accommodation, one came from a Regional Secure Unit, and six (11\%) were transferred from an Interim Semi-Secure Unit that had been established two-and-a-half years before the Unit was opened.

Three patients have remained in the Unit since it opened. Two of these had been transferred from the Interim Unit so they have been in a secure environment for over five years. Excluding these two patients, the average length of stay has been 5.7 months (range three days to 36 months).

Fifteen $(36 \%)$ of patients have remained informal throughout their stay. Eighteen $(40 \%)$ were detained under Sections 2 or 3 of the Mental Health Act for some or all of their stay, whereas ten $(24 \%)$ were admitted under Sections 35, 37 or 38 of the Mental Health Act (1983), of whom one is subject to Section 41 restrictions. The majority of offenders are now admitted under Section 38 (Remand Order), which allows assessment for up to 12 weeks before a decision is made to admit for a longer period. One person was subject to a Probation Order.

Of the 46 discharges from the Unit, $20(44 \%)$ were initially to one of two other adult treatment wards. Sometimes this had been a planned move. Often it was because the individual no longer required active treatment but suitable community services were not available. This problem is discussed below. Fifteen $(33 \%)$ of discharges were to the parental home or independent accommodation, $8(18 \%)$ were to local authority accommodation. Two individuals were referred back to the Court. One was transferred to a Special Hospital after causing a serious fire on the Unit.

Examination of prospective admissions over an 11 month period indicated that of 14 referrals discussed, eight were subsequently admitted. In three cases the need for admission did not materialise. In a further three cases it was agreed admission was not appropriate for separate reasons. In one, detention was not appropriate but it was considered that the patient would not have stayed on the Unit as an informal patient, in another the Unit could not provide the security required (the patient remained in a Special Hospital), and the third patient required a specialist neurological rehabilitation service. 


\section{Comment}

The Unit has in effect acted as a sub-Regional Secure Unit since it was opened. With the exception of one patient transferred to a Special Hospital and one expatient awaiting trial who may require admission to a Special Hospital (each for setting fires), there has been little evidence of need for provision with greater security. No-one has been refused admission because of the belief that the external security of the Unit would be compromised by the individual.

There are, however, considerable problems in managing a number of patients, some of whom display particularly long-standing maladaptive behaviours, in a group whose problems vary widely. We believe such patients should be managed in much smaller, separate groups for much of their working and leisure time. This would require more flexible, homely, accommodation. Clearer policies or contracts on admission from local Districts (Murphy et $a l$, in press) would enable more efficient use of places, with fewer patients remaining 'stuck' on the Unit.

Some of the problems relate to issues discussed by Grounds (1987). He commented on the difficulty in justifying prolonged treatment of some patients when the link between successful psychological change and a reduced risk of dangerous behaviour is uncertain. Nevertheless, a major formal change in a review of the Unit's operational policy has been the recognition that many individuals require in-patient treatment lasting for considerably more than two years. For example, one woman patient, diagnosed as suffering from borderline personality disorder in addition to mild intellectual handicap, and who had spent four years in a Special Hospital, was admitted under a Hospital Order subsequent to making threats to kill a child. She suffered sexual abuse as a child, after losing her mother before her early teens. Her two children have both been taken into care. To help her resolve some of her feelings of bitterness over her sexual abuse as a child, and loss of her children, and to gain some self-control over her anger and her self-injurious behaviour, in-patient treatment is envisaged for at least three to four years, including a psychotherapeutic approach and teaching of coping strategies.

Another detained patient developed an apparently intractable cycle of staff attacks and frequent $a b$ sconding, assaulting a woman patient on one of these occasions. After three years of counselling, together with control of his aggression through the use of lithium, staff attacks have virtually ceased and his self-control over his verbal behaviour has greatly improved. Continued counselling over at least a further two to three years is envisaged before he will be able to control his urge to abscond sufficiently to enable discharge to an unlocked ward.

Outstanding difficulties which the Unit still faces include the following.

(a) Discharge subsequent to treatment often remains very difficult, owing to lack of local provision of facilities with sufficient staff supervision. Ten people remain hospital inpatients as a consequence of such difficulties.

For example, one individual had a history of forcing his sexual attentions on less able people. He was admitted as an informal patient and completed treatment including a programme of education about sexual behaviour, social behaviour and mutual relationships. He continues to require supervision and remains on the Unit, although he would be more appropriately accommodated in well staffed local provision were such available.

(b) Siting of the Unit within the grounds of a large hospital to some degree restricts opportunities for learning social and other skills needed for living in the community.

(c) Congregation of individuals with maladaptive behaviour enables them to learn from or exacerbate each other's behaviour.

(d) A need for more provision to accommodate patients who have responded to treatment over an extended period, and who would benefit from a less supervised smaller setting of patients.

\section{References}

Department of Health and Social Securrty (1974a) Security in NHS Hospitals for the Mentally III and the Mentally Handicapped (Glancy Report). London: DHSS.

(1974b) The Interim Report of the Committee on Mentally Abnormal Offenders (Butler Report) Cmnd 5698. London: HMSO.

GROUNDS, A. T. (1987) Detention of psychopathic disorder patients in Special Hospitals: Critical issues. British Journal of Psychiatry, 151, 474-478.

MURPhy, G., Holland, A. \& Fowler, P. (in press). MIETS: A service option for people with mild learning disability and challenging behaviour or psychiatric problems. Mental Handicap Research.

OXFoRd REgIONAL HEALTH AUTHORTY (1976) A Survey of the Need for Secure Psychiatric Facilities in the Oxford Region. Oxford: Oxford Regional Health Authority.

Royal College of PSYchiatrists (1981) Secure Facilities for Psychiatric Patients-A Comprehensive Policy. London: Royal College of Psychiatrists. 